B. APL, 46. $2008(137-162)$

\title{
EL NEOINDIGENISMO COSTUMBRISTA DE PORFIRIO MENESES
}

\author{
Manuel Pantigoso \\ Academia Peruana de la Lengua
}

Iniciándose dentro del neorrealismo rural, de cholismo mestizo, de delicado y poético impresionismo en la descripción del paisaje y de penetración en la atmósfera psicológica que retratan los problemas de los personajes, Meneses ingresa en las otras vertientes de la narración: la fantástica y la maravillosa, sin someterse a ellas. Surgido cuando todavia no se habia desarrollado a plenitud lo mágico y la fabulación esotérica, y más bien asediado por el regionalismo campesino, este autor ayacuchano se asomó a ellos con la libertad de quien encuentra otras maneras de ensanchar su palabra. Sin embargo, su escritura permanecerá con su mismo latido, fuerte y generoso, con humor de tierra, de agua y cielo, y con un encendido fuego que trae una oralidad muy antigua al unir, en quechua y español, la mansedumbre con la risa $y$ la rebeldia y con ese saber amar al amor y a la esperanza dentro de un costumbrismo trascendente. Este articulo trata de esta impronta de Meneses y de sus postulaciones estéticas, a través no solo de la narración sino, también, de la poesia, el teatro, el ensayo y la traducción. 


\section{Introducción}

Porfirio Meneses es uno de los grandes e intensos escritores del Perú, perteneciente a aquella deslumbrante "Generación 30-36", la de Ciro Alegria, Arguedas, Mario Florián, por citar solo ciertos nombres de relieve, que en su escritura se orientaron a revelar la crisis humana a partir del hombre indigena y autóctono; escritores ligados a la oralidad de la palabra, convocados y comprometidos, porque ella expresa al hombre inmediato unido a la tierra, a su realidad y a sus problemas.

La experiencia indigenista de los años 20 y 30 aparece como consecuencia de esa lucha por superar al Modernismo. Los escritores de aquellos años asimilaron la estética vanguardista por significar una protesta y una ruptura de los formalismos clásicos. El Neoindigenismo, por su parte, habria de superar la estridencia y las disonancias del discurso presente en cierta vanguardia indianista. Sin embargo, en las obras surgidas a partir de esta tendencia no desaparecerá el acento nativo sino que su escritura seguirá revelando la esencia terricola, las raices del hombre y su paisaje.

En la obra de Porfirio Meneses se congregan las estructuras de un mestizaje lingüistico siempre creador $y$, por eso, renovado a través de modismos, "ruralismos", quechuismos, que saben enlazarse con el presente para establecer un nexo umbilical, histórico, en donde el tiempo recogido siendo animista es, también, heroico porque plantea una proyección futura, siempre esperanzada, junto a la existencia.

\section{I}

Porfirio Meneses Lazón nació en Huanta, Ayacucho, el 30 de octubre de 1915. Actualmente tiene cerca de 93 años. En ese pueblo pasó sus primeros años, asi como en Marcas un distrito aledaño. A los siete años, luego de la separación de sus padres, viajó con su madre del pueblo natal a la capital: "Lo hice amarrado a un caballo -dice-, transitando por las altas punas y mirando de lejos el rio Mantaro". Los primeros años en Lima fueron muy duros para la madre quien, trabajó en distintas casas limeñas: "De esta manera yo podia subsistir, a veces bastante bien, 
porque estando al alcance de ella los alimentos de las casas en las que se empleaba, ocurria que yo participaba de lo mejor, a ocultas de los dueños". Los estudios primarios, realizados con muchas interrupciones, los concluyó, finalmente, en una escuela fiscal. La secundaria la hizo, primero, en el colegio Guadalupe, y los tres últimos años en el plantel que luego se llamaria Alfonso Ugarte. Aqui inició su labor literaria dirigiendo una revista satirica llamada El mosquito, con temas internos del colegio que se confundian con las vicisitudes propias del régimen de Sánchez Cerro. Asi se fue configurando ese espiritu irónico y humorístico unido al compromiso social y humano.

Desde 1935 -año en que concluyó sus estudios escolares- hasta 1940, está en Huanta y Acobamba. No habia posibilidades económicas para seguir en la universidad y era preferible volver al terruño. Asi, vagó esos años, participando como cantor ambulante en cuanta reunión o velada artística se llevara a cabo, haciendo vida común con los indios, principalmente con los del distrito de Marcas, en donde su familia tenia una pequeña chacra. De esta manera se fue documentando objetivamente sobre la vida y psicologia de su pueblo para recoger esa experiencia humana que luego volcaria en sus personajes. Respecto a esta etapa el escritor diria en una entrevista que le hicimos:

"[...] de 1935 a 1940 senti mis ancestros cobrizos con fuerza incontrastable. Y comencé a escribir para reivindicar a mi tierra, Ayacucho, Huanta, a la que no advertia en la literatura peruana. La gente sufrida, fuerte pero a la vez dulce y alegre que conoci, me hicieron pensar que bien valia ser mostrada, rescatada, como expresión de una tierra bravia y bella. Y configuré mis propios indios, tal vez terribles en algunos casos, pero siempre alegres, risueños, padeciendo sin llanto y antes bien con frases picantes a flor de labio"!

Asi hay que leer sus innumerables cuentos, con las vivencias recogidas de la propia tierra. El poema "Retamayoj Marcas", que aparece en su libro Suyaypa Llaqtan, es altamente ilustrativo:

1 En revista Moneda. Año V. Octubre-noviembre. N.0 52.53. Lima, 1992. 
Bulle el viento, sube, desciende, rasga la distancia y abre las compuertas del trueno, ¿es asi el camino a Dios?

Menta del azote y la caricia del vendaval, aqui es el ser, aqui donde siento la tierra y la lluvia trasciende como una flor, donde cantan los perros pastores, Retamayo, y deslie una antigua sonrisa don Claudio Bravo, campesino.

Aqui, atrio de marcas, Retamayo, donde se quiebran las lejanias, abra de los vientos novia.

Pero también está -en otro poema- el rio de Marcas, el rio Tánkar, testigo de la historia del pueblo; y los antiguos chaskis, o los soldados españoles, o los héroes populares, inclusive de su propia familia:

pongos, indios mitayos,

tánkar;

rebeldes de Navala Huachaca, soldados de Vivanco, patriotas

de Miguel Lazón

y Tayta Cáceres, tánkar

de las caricias/ violeta

en Muyurina, camino,

en Retamayog, camino,

tánkar de mis abuelos 


\author{
y mi sangre, \\ $\mathrm{y}$ mis viejos acentos \\ apagados, lila".
}

En 1941 se encuentra nuevamente en Lima e ingresa a la Universidad de San Marcos. Desorientado, recorre sucesivamente - sin graduarse- las Facultades de Letras, Derecho, Ciencias Económicas y Educación. Solo muchos años después -en 1979- se titula de licenciado en Lengua y Literatura. En su primer año en la universidad obtiene Mención Honrosa en los Juegos Florales, en el área de Ensayo, con su trabajo titulado "Viaje a los predios del espiritu”. El año 1947 gana el Primer Premio en Narración con su obra Campos marchitos. El segundo premio lo obtuvo Carlos Eduardo Zavaleta, que era entonces un joven estudiante de la Facultad de Medicina.

El Jurado que galardonó a Meneses estuvo compuesto por Manuel Beltroy, Rodolfo Ledgard, Estuardo Núñez, Augusto Tamayo Vargas y Alcides Spelucin. Durante la entrega de los premios, en el Teatro Municipal, el discurso lo ofreció el Dr. Tamayo Vargas quien, a nombre del jurado fundamentó asi su decisión:

"Por su estilo moderno y simple a la vez, por su peruanisimo sabor y la variedad de sus motivos, hemos juzgado merecedor del Primer Premio por los breves relatos reunidos en el volumen Campos marchitos cuyo autor, tras el seudónimo de Quilli Huara, resultó ser el señor Porfirio Meneses Lazón, alumno del segundo año de la Facultad de Educación. "El secreto", "Tifus", "Campos marchitos" y "La viuda", que constituyen el trabajo elegido, antes que revelar particular imaginación o habilidad técnica para el cuento, acusan una moderada tendencia a la estampa, en virtud de la cual el autor confiere a sus relatos leves acentos costumbristas, acertadas notas de ambientes caracteristicos, manteniéndose a distancia, sin embargo, de la literatura folclórica habitual. La superioridad de Campos marchitos sobre los demás trabajos, a nuestro juicio, reside en la calidad de su prosa sobria y espontảea que, esperamos, pueda llegar a desarrollarse sobre el área menos fácil de la novela propiamente dicha". 
Es oportuno recordar que el cuento "La viuda", que forma parte de Campos marchitos, fue teatralizado muchos años después por Rafael del Carpio con el nombre de "La chicha está fermentando", que tuvo mucho éxito.

Al lado de la labor literaria, Porfirio Meneses inicia, en 1946, la actividad teatral que tanto significaria en el desarrollo de su vida cultural. Primero es nombradoadministrador del Departamento de Teatro Nacional Escolar del Ministerio de Educación. Luego, de 1948 a 1952, es jefe de la Sección de Teatro en la Dirección de Educación Artística y Extensión Cultural. También será profesor de Historia del Arte en la Escuela Nacional de Arte Escénico -ENAE- (1946-52), y Profesor de Teatro en el colegio "Bartolomé Herrera", de 1950 a 1954, donde lo conocimos y comenzó nuestra admiración humana y artística. Por entonces habia fundado el Grupo de Teatro Talía, de importante presencia en Lima hasta los años 60. Nosotros formamos parte de esa hermosa experiencia representando a Cervantes, los hermanos Álvarez Quintero, Curzio Malaparte, Camus, Bernard Shaw, y tantos más, desde el Teatro Segura hasta el Norte Chico, Canta y Jauja. Recordamos, también, que el grupo llegó a representar una obra hasta entonces desconocida de Ciro Alegria: "Selva", de tema amazónico.

Como autor teatral Porfirio Meneses comienza en 1954, cuando la ENAE publica su obra La Princesa del mar. Como jefe del departamento de Actividades Educativas de la G.U.E. Mariano Melgar trabaja desde 1953 hasta 1980. A partir de 1963 enseña quechua y literatura en la Universidad Federico Villarreal, asi como en otras instituciones. En 1964 gana el $2^{\circ}$ Premio del Teatro Universitario de San Marcos (TUSM) con El árbol y la boda, y posteriormente viaja a Chile con la delegación del grupo de teatro "Histrión" para cumplir, entre otras labores, la de actor, teniendo como compañero en estas lides al poeta Alejandro Romualdo, recientemente fallecido. En 1962 aparece su famoso cuento: "El hombrecillo oscuro", antologado en Nuevas voces de América Hispana con traducción al inglés de D. Flaco y Maribel Alegria, al lado de Cortázar, Roa Bastos, Cardenal, Rulfo, Benederti, Parra, Arreola, Donoso, Pero su prestigio literario se afianzará a partir de 1965 . Ese año gana, entre 400 concursantes, el 
Primer Premio y la Primera Mención Honrosa con los cuentos "Aquel hermano ausente" y "Alcornoque", en el evento organizado por las revistas Cuadernos, de Paris, y 7 días, de Lima. El segundo premio fue para Carlos E. Zavaleta, con el cuento "La amistad" y el tercero para Eugenio Buona, con "Los hijos". En aquel año se consagra, mediante el Premio Nacional de Fomento a la Cultura "Ricardo Palma", con su libro Solo un camino tiene el río, que seria publicado diez años después, en 1975. Ya desde 1965 habia comenzado su asistencia a los más importantes congresos de narradores: en Arequipa (1965), en Cajamarca (1971), en Ayacucho (1982), en Trujillo (1983) y en Lima (Latinoamericano de Escritores, 1987). En 1979 aparece en la Antologia del Premio COPÉ, con su cuento "El zorro". En 1974 habia reeditado su valioso libro Cholerías, aparecido en 1946. En esta nueva edición incluyó textos de Campos marchitos (1948) y de El hombrecillo oscuro y otros cuentos (1954). También, en ese año de 1974, aparece la antologia Huanta en la Cultura Peruana, en colaboración con Teodoro Meneses y Victor Rondinel, libro que expresa, junto con su importante libro de poesia Suyaypa Llaqtan, País de la esperanza (1988), uno de sus intereses mayores: la revalorización y difusión de la lengua quechua y de su literatura.

\section{La narración}

Hay dos etapas en la narrativa de Porfirio Meneses; la primera se ubica geográficamente en Huanta y tiene todo el marco del impresionismo del campo y del paisaje andino; la segunda introduce el quechua en la escritura, al punto que existen algunos cuentos inéditos escritos totalmente en este idioma. A esta segunda etapa pertenecen, de la misma manera, aquellas narraciones con personajes de la urbe.

Cholerías, publicado en 1946 junto con cuentos de Alfonso Peláez Bazán y Francisco Izquierdo Rios, finalistas todos del Concurso Fomento a la Cultura, contiene nueve cuentos en los que lo regional ligado al hombre y sus problemas le proporciona al relato una intención dramática, honda y humana. Destacan, sobre todo, los cuentos "La Procesión", "Arrieros" y "La Fuga". En los dos primeros hay bellas descripciones, sobre todo 
en "La Procesión", en donde esa gracia teñida de humor mestizo, tan tipica en la narrativa del autor, colorea los episodios teniendo al lado el tiempo que todo lo compone y todo lo marchita. Este último es el caso de "Los Arrieros" en donde hay el castigo de un "cholazo ladrón" de parte del hombre de la puna, muchas veces frio, áspero y cruel como el mismo paisaje. Este penetrar en el mundo psicológico del poblador de la sierra aparece, igualmente, en "La Fuga", excelente cuento que en 1941 fuera leido por Josẻ Diez Canseco, en Ínsula, cuando era presidente de esa institución Josẻ Gálvez quien se refirió elogiosamente al texto diciendo que alli habia una "visión colorida como los mates de Ayacucho". Diez Canseco lo impulsó, alborozado, para que continuase por esa brillante ruta que el autor habia escogido. El cuento en mención, "La fuga", trata del conflicto psicológico de un indigena de edad abandonado por su joven mujer para caer en los brazos de "un cholo altazo, fornido, que le servía de beber con pícara asiduidad". El marido la buscará afanosamente hasta que la encuentra, la perdona, golpea al robador y trae a la mujer de vuelta al hogar; aqui todo está escrito con una gran capacidad para delinear a los personajes y penetrar con agudeza en sus caracteres, pero también con emoción y algún espíritu romántico, casi trágico. Al lado de estos tres cuentos está "Casicha", con la presencia de la campiña de Huanta y todo el sabor terrígeno depositado en los amores sencillos que se resuelven bajo la sombra de los maizales.

En estos cuentos desfilan motivos costumbristas de la sierra de Ayacucho teniendo como protagonistas a personajes vigorosos que alcanzan la prestancia de viejos idolos al guardar sus antiguas fuerzas para estallar cualquier dia. Junto a esa "violencia de ojos y músculos" está la violencia de la soledad, del rio o de la tormenta. Este clima del castigo despiadado y del grito amargo se manifiesta precisamente en "Los Arrieros", ya citado. Sin embargo, como atenuándolo todo, aparece el estilo sobrio, sin estridencias, con colorido y hondura de sentimiento, a partir del paisaje de la naturaleza y de las voces indigenas con sus giros y dislocaciones del lenguaje, de lo espontáneo y natural, de la ingenuidad y la sencillez, del gran sentido humano y el humorismo de la mejor calidad. Dueño de una imaginación sin retórica, Meneses expresa frescos, armoniosos y fuertes cuadros de la vida serrana de los pueblos y aldeas ayacuchanas, con 
argumentos que pueden ser breves y sencillos pero resueltos con una gran jerarquia, como cortas obras maestras. En ese espacio de la narración lo que más interesa no es tanto el conflicto cuanto esa luz que surge de la psicologia de los personajes y de sus peripecias.

En El hombrecillo oscuro y otros cuentos, que lleva dibujos de Sabino Springett, hay 20 cuentos de temas variados, hilvanados por su tono peculiar, fluido, donde no hay estrépitos ni colores chillones y si el contraste de los excesos y el control de los desbordes a través del humor, de la suave melancolia, del escepticismo, capaces de atenuar las pasiones como un barniz de luz suave que solo se fractura cuando aparece el suceso mágico. Con este libro comienza a aparecer en la narrativa de Porfirio Meneses el estilo directo, reposado, apacible, en tono menor, y sin embargo firme y penetrante en el candor del ambiente campesino unido a la psicología del hombre andino: entre las vertientes de la vida y de la muerte. Los mejores cuentos son, precisamente, los referidos al mundo agrario, tal el caso del que da nombre al libro; peor igualmente de "El pariente Rude", o de "Amor como nube" cuyo encanto narrativo radica en su gran soltura y en su desplazamiento natural, así como en esa actitud que muestran los personajes de aguardar, solitarios y confiados, en una redención material y espiritual que habrả de llegar inexorablemente. Hay ahora una mezcla de impresionismo y de expresionismo en la unión tempo-espacial de subjetividad lirica y testimonio objetivo del ambiente o atmósfera, asi como en el enigma psicológico del hombre y de su aventura vital.

El espiritu general que anima a El hombrecillo oscuro y otros cuentos expresa ese otro espiritu, el de su autor, que ni ostentoso ni prolifico -más bien ensimismado y reflexivo, y con el humor siempre a su lado- ha trabajado su obra sin temor a la falta de estímulo ni a las rivalidades, sin autobombos, con su sólida vocación y su impronta siempre renovada y honesta. Asi, su obra, mezcla de psicoanálisis y de creencias y costumbres tradicionales del pueblo - en la cual no faltará cierta fabulación y magiaha ido creciendo lentamente, sin sobresaltos. 
Solo un camino tiene el río está entre el regionalismo campesino o provinciano -porque también hace regionalismo el que escribe sobre las calles de una gran ciudad- y el relato fabuloso. Este nuevo libro tiene prólogo de Luis Alberto Sánchez, quien dice:

"[...] los cuentos de Meneses participan de la pasión por el paisaje (ámbito externo y extrahumano) y del amor, concebido románticamente, es decir, como impetu incontenible, sea que se trate de un amor ideal, sea que se trate de sexualidad. Son reflejos quizá tardios de las novelas de Gallegos, Rivera, Rubén Romero, Güiraldes, Alegria e Icaza".

Este texto -que a nuestro entender tiene más de precursor que de "reflejo tardio" - integra cuentos psicológicos ambientados en la ciudad; sobre ella ha dicho su autor: "Rompe la tradición de mi estilo y mi tratamiento de los temas". En otra parte de estas declaraciones aparecidas en el diario La Crónica (18/01/75), señala con gran precisión:

"I...] se me ha tildado de indigenista, término limitativo que se me ha aplicado hasta diria que con un poco de mala intención. Yo me considero más exactamente un escritor costumbrista. El indio ocupa un lugar esencial en mi temática literaria, pero no es el único. El principal si. Pero he cogido también temas urbanos y personajes negros, chinos, mestizos y otros. Mi intención es ampliar mi tarea intelectual".

Esta ampliación -que es una caracteristica de su espiritu inquietocontinúa su labor literaria en la búsqueda de una mejor sintonia con su espiritu. La impronta aparece claramente en Solo un camino tiene el rio, donde apenas hay dos cuentos campesinos: "Venturano en la noche" y "Los hombres y ella", el primero sobre la leva para el servicio militar y, el segundo, sobre las relaciones entre hombre y mujer. En ellos el tratamiento del problema y la técnica segura y tradicional, trascienden el ámbito campesino hacia una perspectiva más universal. Los otros once cuentos tienen ambiente urbano, y en ellos se comprueba el gran dominio de las situaciones y de la psicologia de los personajes de Lima y de otras ciudades del Perú. Usando la técnica del punto de vista objerivo, dentro de un contexto social que a veces puede ser desgarrador, aparecen 
temas como el sexo, la crueldad de las relaciones humanas, la sordidez de las pasiones. Hay un acercamiento asombroso a la realidad inmediata, caracterizada por un control lúcido y consciente, sin tremendismos ni sentimentalismos. Estas constantes están bien representadas en el cuento "Alcornoque", ganador de la Primera Mención Honrosa del concurso organizado por la revista Cuadernos de París. Aqui hay una penetración en el alma del negro pobre y valiente, de gran fortaleza fisica, que acude al médico para curarse de una herida provocada por la caída de un ladrillo deslizado desde el andamio hacia su cabeza, envuelto por un ambiente tragicómico y con el lenguaje del habla popular negra, mezcla de ironia acerada $y$, a veces, de fino humor.

Solo un camino tiene el río es pues importante porque el autor se introduce, con más decisión, en el relato mezcla de lo fantástico y del realismo maravilloso, con lo cual -insistimos- continúa ampliando su tesitura narrativa. Tal es el caso, sobre todo, del último cuento: "La aventura", en el cual se parte de la realidad local y se llega, por la fascinante realidad de la civilización incaica, hasta un misterioso valle sagrado, dentro de un contrapunto entre el pasado remoto y las preocupaciones actuales. El texto, escrito con verdadera maestria, acentúa el ya citado punto de vista objetivo pero, también, el recuerdo, la interpolación y la inclusión de tiempos -el actual, primero, y luego, el tiempo referido; y dentro de él, un tiempo más antiguo todavia, como un sueño que se sueña, azulino o fosforescente-; y al lado de todo ello, la interrupción del relato para crear más suspenso, con el espacio intermedio entre la realidad y el sueño, la ruptura del tiempo y del espacio, la presencia del narrador testigo y del narrador participante. "La aventura" es profundamente significativa porque abre otras compuertas en la narrativa de Meneses y "aventura" otros caminos. En esta línea está también su cuento "El Zorro", incluido en la antologia del Cuento COPÉ 1979, que con un desarrollo esplendente narra -en quechua y español- las peripecias que están en la oralidad andina. Igualmente habria que colocar en esta dirección su obra de teatro La Princesa del mar (las islas de Pachacámac), 1953, que es una adaptación para adolescentes de una leyenda consignada por Francisco de Ávila sobre el miro de las islas de Pachacámac. En general, podriamos decir que esta linea fantástica y mágica de la nueva narrativa de Porfirio 
Meneses se emparenta con su teatro, en donde ya existen esos ambientes. Efectivamente, al lado de La Princesa del Mar están El árbol de la boda, que es una historia de una pareja de jóvenes girando alrededor de un árbol revestido de regalos en la sierra, con amoríos y peripecias de carnaval; y también se encuentra en esta perspectiva la que viene a ser, hasta ahora, su obra teatral de mayor alcance: Takora Motor's - siempre tenemos un mañana que esperar, que pinta el mundo alucinante del lumpen limeño.

\section{La Poesía}

Como una natural confluencia del tono delicadamente poético que aparece en la mayoria de sus cuentos -especialmente en las referencias al paisaje y a los seres que lo habitan-, y del interés en expresarse en el idioma raigal para volcar mejor sus vivencias más entrañables, Porfirio Meneses llega a la poesia a partir de un excelente libro: Suyaypa Llaqtan. País de la esperanza, publicado solo en 1988 aunque de larga gestación. Escrito primero en quechua, la traducción del propio autor al español nos ha de permitir efectuar algunas calas para ofrecer una mejor aproximación a la intimidad del escritor $y$ a sus recursos expresivos. Veamos. El libro está estructurado en dos partes: "Cantar del Júnej" y "El dolor y los anhelos". El contraste se da entre la voz elemental, bucólica e ingenua, y la inflexión más elaborada y profunda. A este respecto, el autor ha señalado que en quechua no hay todavía costumbre de otras formas de expresion; frente a esta tradición, apunta:

“[...] en la segunda parte si trato de probar las aptitudes del idioma por formas más modernas, jugando un poco más con los vocablos y la estructura moderna, [...] con los vocablos y la estructura oracional".

Aqui tiene papel importante esa peculiar sonoridad del idioma quechua que trata de ser volcada en el nuevo idioma.

"Cantar del Júnej" está marcado por un suave impresionismo, de dulce tristeza, al desvanecerse el tiempo, los recuerdos y las ausencias inacabables surgidos de un mecido ensueño que se irradia a la amada, 
"sutil colibri de luces"; todo con la transparencia del cristal, a la manera de una acuarela en la que hasta el mismo dolor parece diluirse en el agua de la atmósfera. La delicadeza del lenguaje aprehende el tiempo y el espacio, surcados de caminos y montañas en donde crecen flores silvestres y, arriba, el color es verde y plata. Una llovizna, como ilusión iridiscente, le pone pátina de melancolia al paisaje y es el impulso para buscar los espacios amplios: alli están los sueños que traen los nuevos vientos y dibujan los arcos iris, el color violeta de la fragancia, las pequeñas dulzuras; en el trasfondo espejea el dia, y hay el aguardar permanente de una voz infinita, de un amor de miel en los atardeceres, con la alegria gorjeando en la siembra feliz, y, al lado, el sosiego, el murmullo, y aquella luz sin herida en los ojos, solo suspendida en la brisa reverberando en la levedad de unos pasos que ocultan el dolor, el olvido, las injusticias:

¿Quién ronda felino,

mi humilde chozuela

de miserias y espinos?

¿Quién da a la noche

mirar de serpiente?

¿Quién hace del silencio

letal cuchillo escondido?

aunque no lo quiera,

aqui,

pozo de soledad y olvido,

solo un atado de penas guarda!.

(“QQuién...?”)

Pero la luz serả siempre el simbolo totalizador del descubrimiento y la afirmación:

Y el sol, el sol

- mariposa de tiempo y oro-

descubre el alma de las cosas 
y nos siembra/ de flechas y rumbos

el corazón.

("Vete ya, señor")

La segunda parte del poemario Supaypa llaqtan, "El dolor y los anhelos", es, como hemos dicho, más reflexiva, y, tambiẻn, más dramática y comprometida con la elaboración de un lenguaje que muestra las noches amargas, los sufrimientos y los odios antiguos de un "Pais del agua/ del canto y de las penas", que lleva, ahora, el enraizamiento del dolor y esas zozobras que "nos ocultan el alba/ tras el estallido/ sin norte...", invocando sin tregua a la vida frente a los malos presentimientos, las desilusiones, los desencantos. La poética del autor aparece, de pronto, ensombrecida de olvidos, "helando sus pasos":

Dile que no estoy

dile

que murió de moscas,

la palabra que llevaba

alada

de sueño, en sueño

desde el corazón a la esperanza.

("Aquel corazón sellado")

Y sin embargo, al final, siempre estará la luz axial para sustentar el amor, la paz, la libertad:

Dejadme que diga

que amo la luz porque sea vuestra,

porque la hizo Dios

para ti, para aquél,

y los hijos de los hijos

de los hijos,

para

la sonrisa musical

de los peces $y$ las flores.

("Ara"). 
Este sentido de alegato a favor de las raices pasadas y de la afirmación de las fururas aparecen en algunos poemas, como en "Suaves ojos de la montaña", con el "tánkar de mis abuelos/ y mi sangre,/ y mis viejos acentos/ apagados, lila"; también en el poema "Por las cosas buenas", que impugna la destrucción y el odio y cobija al amor, como un niño humilde y desamparado que, tiritando, se coloca al lado de la luz y del calor:

\author{
Mi aldea, sutil y añejo \\ adobe ingenuo, \\ maíz tostado se acurruca, \\ al paso del viento/ y sus sospechas, \\ de fuego y rencor.
}

La vida, la vida,

la vida aủn treme

frente al leño

aterido, confidente.

Una experiencia literaria que demuestra el gusto y el regodeo por la sonoridad y la musicalidad de la palabra -propio, por otro lado, de la literatura oral y escrita del mundo andino- es el libro inédito Rit-mos-rit, presentado hace muchos años para el Concurso "José Santos Chocano", sin ningún éxito. En este texto -que quisiéramos ver publicadoMeneses experimenta el plano de la sonoridad de la construcción verbal, especialmente de la palabra, la silaba y la letra. Dejando de lado ese aspecto inteligible del complejo lingūistico cuya articulación sintáctica se refiere a algo, el autor trabaja solamente con el aspecto audible, es decir, con la materia acústica: el tono, el ritmo, la acentuación, la rima, la aliteraciỏn, etc., que expresan actitud y estados de ánimo del hablante. Esta materia acústica es la que surge, por ejemplo, en la "lectura silenciosa" en donde hay una suerte de representación o imagen del sonido en la interioridad del lector. Es la "huella psiquica", según palabras de Saussure, que permanece presa en el cerebro. Veamos y leamos el estrato físico -gráfico y sonoro- de uno de los textos que aparecen en el libro cirado, recordando, antes, que Porfirio Meneses fue, y sigue siendo, un enamorado de la guitarra y del canto, para los cuales siempre tuvo cualidades sorprendentes. Advirtamos, 
previamente, que los textos tienen en sus originales bloques de distintos colores, como insinuando una recitación coral dialogada. La música y el teatro, las dos pasiones del autor, estarian involucradas. Reproducimos un fragmento de la primera de las diez propuestas rítmicas y visuales que componen el libro Texnot, con sonidos infantiles, reminiscencias negroides, sonoridades del idioma francés, etc., que se articulan dentro de una especie de jitanjáfora:
Sa nui san
de si ma là
de si yam bé
na na su de la
a sui ba san de se
de si la la yu san si
asca vi randé
il se míride van té
alirante alirante
de si masan
de si ma yam be
a na vilar de sen...

a sui

a sen.

En el texto N. ${ }^{\circ} 10$, el juego a base del nombre de los numeros se hace ligeramente inteligible, prevaleciendo la intención ritmica y sonora:

Dos dos dos seis no sss

die die su ie zu no

cua dis cin tro dos sie

co tres te cin nue

co tres no dos sei ve

$5-10$ 
o no tres o no cin nue

cho sei no do - sss

die zi die zi no

sei s - iii

no u no u no u

tres te sie doss cua

cin tro dos co

ziro u ziro u

no -10 .

Son textos que fluctuan entre la tierna ingenuidad y el espiritu observador, entre la sonrisa lúdica y el humor corrosivo, entre la luz intima de la música y la luz abierta del color, todo envuelto por la libertad de la palabra y del amor que sintetizan a la más viva humanidad. Estas son caracteristicas propias del temperamento y el tono literario de Porfirio Meneses.

Aquí, en esta demostración de las "aptitudes del idioma" para corresponderse con la modernidad, tiene rol importante aquella peculiar sonoridad del idioma quechua que Meneses trata de volcarla en el espan̄ol. También le servirả, en la dirección contraria, para sus posteriores traducciones de Los Heraldos Negros y Trilce, de Vallejo. El mejor ejemplo de este ejercicio está en sus poemarios inéditos: Cantos de luz y sombra (Akchi pawan llantupa takinkuna) traducido del español al quechua; y Yapa Tinkunakuy (El reencuentro) que son treinta sonetos quechuas volcados en versión libre al español. El primer volumen lleva la siguiente nota: "si la aprendes bien y la practicas siempre buscando su eficacia expresiva, la lengua kechwa no tendrá nada que envidiar a ninguna otra". Con ello, el autor destaca la ductilidad y la soltura de este idioma para llegar a las esencias y a la expresividad creativa. 


\section{Huanta en la Cultura Peruana}

El amplio conocimiento y la plena comunicación con el quechua le permitirán a Meneses publicar el libro Huanta en la Cultura Peruana. Se trata de una Antologia de Literatura quechua, regional y subregional. Literatura que vive con vigor en la vida cotidiana del campesinado peruano, en sus fiestas, ceremonias, danzas, recuerdos, ya estudiada y divulgada por Basadre, Vienrich, Lira, Alencastre, Arguedas, Farfán, Quijada Lara, etc. A ellos hay que agregar a Porfirio Meneses, Teodoro Meneses y Victor Rondinel.

Esta es la Literatura que cantan y expresan los millones de indios y otras capas sociales marginadas, y a veces, analfabetas, a través de sus muchas lenguas nativas habladas por millones de peruanos que han producido, a través de siglos, cantos, narraciones y teatro; literatura ésta que solo ha sido registrada - a veces no de buena forma- en una minima parte.

La selección es excelente porque, más allá de los géneros tradicionales del drama, la poesia y el cuento, aparecen también formas muy poco estudiadas, como la adivinanza, los chistes y los insultos de Huanta y Huamanga. Toda una extensa y caudalosa literatura quechua: teatro, cuentos, leyendas, "huatuchis", "tratanácuy", "huarahui", poesia, etc.

"Cholo Montonero", de Josefina Lazón, es un famoso huayno alli seleccionado en donde aparece la brutal represión del Coronel Domingo Parra durante la expedición de 1896 . El poema tiene un famoso estribillo que manifiesta la negativa del pueblo por revelar el paradero del Montonero Miguel Lazón.

También aparece Puca Hualicha, drama en 4 actos de Artemio Huillca, sobre el que Edmundo Bendezú (en articulo publicado en Última Hora, 11/1/75) dice:

"Tuvo un éxito sensacional cuando fue puesto en escena numerosas veces en Huanta, Ayacucho y Huancayo, con asistencia plena de 
campesinos, durante los primeros años cincuenta y que posee indudables cualidades literarias"

Hay que destacar, además, esa muestra de la mejor tradición de la literatura catequista del s. XIX: "Yuyaymana (Cuarta Meditación)", en donde el sermón, lleno de patetismo, conlleva meditaciones filosóficas y religiosas.

Igualmente los poemas intensos de Juan Ruiz, el traductor de Vallejo al quechua, y los textos de Porfirio Meneses. Ellos, junto a otros, como Alencastre, Arguedas, Lily Flores, Hugo Tello Prado, Eduardo Ninamango Mallqui, han permitido que la actual poesia quechua salga del anonimato de la canción oral.

\section{La Traducción}

Una tarea ardua debió significarle a Porfirio Meneses la traducción al quechua de Trilce, de Vallejo, la obra mảs vanguardista, iconoclasta y polisémica en lengua española. Ya anteriormente habia traducido Los Heraldos Negros, publicado en 1997, por la Universidad Villarreal ${ }^{2}$. En las palabras prologales de este trabajo Meneses escribió que traducir al idioma materno la poesia del gran santiaguino siempre le significó rendir homenaje "a tres entes venerables: la lengua quechua, el pueblo que la habla y el inmenso poeta César Vallejo" 3 .

Porfirio Meneses desea que a través de la obra de Vallejo el idioma quechua - "tesoro espiritual del Perú y América" - se revalorice y vuelva a adquirir su sentido vital. Algunos intentos referidos a los textos

\footnotetext{
2 Después de muchos años traduciendo Trilce, la obra fue finalmente publicada por la Universidad Ricardo Palma; Lima, Editorial Universitaria, 2008.

3 En palabras prologales de Los Heraldos Negros, Edición bilingüe, traducción de Porfirio Meneses. Lima, Editorial Unixersicaria de la Universidad Federieo Villarreal, 1997.
} 
vallejianos se dieron también en otros escritores. Su hermano Teodoro Meneses tradujo al quechua el poema "Masa"4 y el profesor huantino Juan Ramirez, hace poco fallecido, tradujo algunos poemas de Vallejo que divulgó en pequeñas revistas de Ayacucho.

Cabe advertir que el quechua empleado por Meneses es el ayacuchano o quechua miski (dulce), el cual registra algunas variantes respecto al cuzqueño, por ejemplo. Es un quechua de sonidos suaves y melodiosos porque no tiene la pronunciación explosiva de los "sonidos glóticos", manifestados gráficamente mediante el apóstrofo (como en la propia palabra miski cuyo sonido se vuelve oclusivo-explosivo si aparece con dicho signo: misk'i). Esta señal ortográfica es más frecuente en el quechua cuzqueño, fuerte y enfático debido sin duda a la influencia del aimara. El hondo humanismo y la ternura que impregnan los versos de Vallejo acaso tienen una mayor proximidad con esas inflexiones sonoras del quechua miski. Para cumplir con tan dificil pero gratificante empresa, el traductor contó con el aval de su propia pasión e identificación con la poesia de Vallejo, de su conocimiento profundo de la lengua madre (idioma de su infancia, igual que Arguedas) y de su condición de narrador en dicho idioma.

Como sustento de su dominio del quechua Meneses exhibe su revisión y estudio de las gramáticas quechuas de Antonio Ricardo, Diego de Torres Rubio y Diego González Holguin, asi como de los trabajos modernos del padre Juan Maria Chouvens que vivió muchos años en Huanta (completada y publicada luego por Clemente Perraud); también de César Guardia Mayorga, Rodolfo Cerrón, Clodoaldo Soto, Antonio Cusihuamán, etc., sin dejar de lado las novisimas gramáticas de las variantes del quechua surgidas con motivo de su oficialización. Toda su investigación y experiencia la ha volcado en su labor como traductor del quechua al español y viceversa. Sin duda, la versión de Porfirio Meneses tendrá que ser cotejada a la luz de la esencia poética vallejiana que él ha querido volcar.

4 El poema aparece en el libro Homenaje Internacional a César Vallejo, publicado por Carlos Milla Batres, en 1969. Tambien hay alli versiones del poema "Masat traducide al francés, italiano, chino, ruso, inglés, japonés, alemản, portugués. 
En el Perú, César Vallejo es el primero en llevar hasta extremos sorprendentes esa intensificación de la palabra poética, lo que nos permite -lo decimos con palabras de Antenor Orrego- sentir la ilusión del primer conocimiento en donde se han "vaciado las entrañas de trapo y aserrín, tras de haber examinado atentamente la arquitectura de su juguete, tras de haber apartado pieza por pieza todo el montaje interior, tras de haber eliminado todo lo puramente formal en busca de las esencias" 5 . Vallejo -en esa búsqueda angustiada de la palabra justa- fractura y derrumba la propia palabra para descarnarla y vitalizarla, simultảneamente. Desde esta perspectiva será imposible una traducción convencional, por la concentración de significados realizada mediante todo tipo de asociaciones lingüísticas: ¿Cómo volcar, por ejemplo, en otro idioma, el verso: “QQué se llama cuanto heriza nos? ("Trilce II"), si consideramos que "llama" hace también referencia al fuego, y que "heriza" está escrita con "h" porque contiene además a la palabra "herida"?

Sin embargo -confiesa Meneses- he asumido el riesgo de traducir Trilce "porque con ello me gratifico y beneficio a los quechuas hablantes: el labrador que desea regar su predio no se llevará todo el río; solo derivará las aguas que sean necesarias para fructificar su tierra, con lo cual obtendrán provecho él, su familia y las gentes de la población cercana donde irá a ofrecer los productos de su cosecha". El escritor nos está revelando en esta parábola su método y proyección en la traducción de Vallejo.

Es indudable que el escritor huantino ha tenido que internalizar durante años todo ese estado naciente del lenguaje vallejiano, sus sentidos encubiertos, sus veladas reuniones y asociaciones lingüisticas, su significación múltiple, para luego verterlos al idioma nativo, el cual ha de renacer empapado de las sensaciones y resonancias cercanas a lo que Vallejo quiso decir. Sin duda, la traslación de un idioma a otro se dará solo por aproximación, similitud y correspondencia.

El espíritu radicalmente distinto que anima a los dos idiomas -el castellano y el quechua- ha sido su mayor dificultad. Vallejo va por el

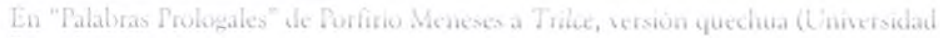
Ricardo Palma). 
camino sencillo del habla coloquial y, de pronto, tuerce por el atajo de una palabra o una construcción inesperada por antigua, extraña o inusual; otras veces la palabra aparece por simbiosis o por su entera invención; y no pocas veces construye una abstracción con frases coloquiales. El esfuerzo es titánico, sin duda, puesto que en el quechua existe, en esencia, la concreción y no la abstracción. Alli está, por ejemplo, el concepto del "tiempo", que Meneses lo explica asi:

"La idea del tiempo como eternidad solo existe en el castellano hablante. Si algo abarca una extensión de tiempo de duración está la palabra 'unayniyud' (lo que tiene antigüedad), o "unarayay" (el tiempo de permanencia). El tiempo en el quechua no es indefinido ni impreciso".

Sin embargo, esta realidad lingüística no le impide al quechua captar e interpretar la modernidad ${ }^{6}$. Aquí radica, justamente, la trascendencia de la tarea impuesta por Meneses: "mostrar la aptitud del quechua para interpretar y expresar la cultura de todo tiempo y manera, y, en este caso, existente en la poesia de César Vallejo"7. Sin duda, un aspecto favorable para ello es que el traducido es también un hombre andino y que existe una fuerte ligazón entre cosmovisión y lenguaje andino. Al respecto, dice Eduardo Grillo Fernández:

"La cosmovisión andina confiere, transmite su modo de ser al lenguaje andino. En el cosmos vivo, en el mundo animal (Kusch, 1962) de la cosmovisión andina, el lenguaje es también, a su vez, vivo. Se trata de un lenguaje vivo en un mundo vivo. La palabra, la frase, tienen vida" ${ }^{\text {. }}$

6 En el prólogo a su traducción de Los Heraldos Negros, Meneses dice lo siguiente, aplicable tambièn a su traducción de Trilce: "Habiase de mostrar también la cabal aptitud de la lengua natisa para ofrecer sin desmedro la expresión contemporánea, incluidas las formas de abstracción que algunos lingûistas y comentaristas pro occidentales han querido negar alguna vez. El autor ha pretendido mostrar una lengua actual y no pasada, un hálito vibrante de modernidad".

7 Ibidem.

8 "El lenguaje en las culturas andinas y occidental moderna", en Cultura Andinat Agrocéntrica, Pratec, Perủ (s/l, s/f), pp. 69-96. 
Sin dejar de aproximarse a la esencia de la expresión tipicamente vallejiana, Meneses ha colocado en su traducción, ciertamente, las esencias vitales, tanto personales como del mundo andino, y se ha identificado con aquello que hiere sus propias antenas y lo acerca a su personalidad sensible. Con todo ello ha logrado culminar con éxito una traducción viva y ejemplar de los textos de Los Heraldos Negros y de Trilce.

\section{II}

\section{La profesión de Porfirio Meneses}

En los eventos en donde ha participado Porfirio Meneses, el tema del esclarecimiento del papel del escritor ha sido relevante. Él ha dicho que el escritor realiza permanentemente la tarea de crear y recrear la patria a través de la escritura. De ahi su condición de alterador y desmitificador del orden establecido, que es su lucha permanente contra el esnobismo y las falsas posturas. En Cajamarca (1971) declaró que los escritores cumplen una tarea básica:

“'[...] ellos son los culpables, porque miran a la gente, las escudrinan, las estudian y, finalmente, se pronuncian. Aunque no todos tengan una militancia partidaria, cumplen un rol social que en nuestro tiempo es la denuncia".

Y sobre el humanismo en el arte y la expresión de la literatura, Meneses declaró también en Cajamarca, y de paso definió su propia estética:

"[...] la emoción en el Arte hay que buscarla en lo que más se acerque o se llegue a nosotros, al hombre; en lo que mejor pretenda servir nuestros anhelos, nuestras ilusiones, nuestros deseos. El arte anterior tiene, es verdad, un valor eterno, pero puede decirse también estereotipado, congelado, útil como base o cimiento para el arte actual. Pero éste, debe movilizarnos, debe expresar la suma de nuestra percepción y de nuestras ansias totales. El arte debe 
estar al servicio del hombre y ser su palabra. Debe ser el hijo de la cópula entre él y las cosas. La época presente nos muestra nuevos panoramas, nuevos problemas, y nuestras reacciones tienen que ser nuevas también. Pero la expresión no debe salir del espacio que hay entre las cosas y nosotros. Aquellos que visten la belleza con rebuscadas y alejadas abstracciones, nos la están hurtando".

Esta posición de Porfirio Meneses es coherente con su misma obra y, además, esclarecedora de su temática y de la estrecha relación que siempre ha establecido con ella en el sentido de plasmar vivencias auténticas, tanto del campo como de la ciudad. "Vivir para luego escribir sobre el vivido" pareceria ser la oriflama estética de Meneses, quien en un reportaje ofrecido a Ana Maria Portugal, en el diario Correo (11-05-71) decia:

"Yo nunca he intentado precisar, ni siquiera saber, como he entrado en este oficio de escribir, yo he vivido en los estratos inferiores de la sociedad, los más humildes, y he vivido también mucho e intensamente en el campo".

En 1955, Mario Vargas Llosa recogió importantes declaraciones de Porfirio Meneses respecto a su vida y obra, especialmente su enfoque del indio peruano a partir de la convivencia con ellos: "Creo haber escrito guiado principalmente por el objetivo de mostrar a mi pueblo sin las erróneas creencias sobre la tristeza y la negatividad del 'indigena'". Y en relación a la naturalidad en la escritura, producto de esa simbiosis entre las cosas y el sujeto receptor de ellas, Vargas Llosa acota que para Porfirio Meneses una situación inicial y un personaje son el origen de todos sus cuentos, "los mismos que, generalmente, se estructuran temáticamente mientras escribo" (Suplemento Dominical de El Comercio, 16/12/55).

Sobre la visión del campesino, producto de su entrañable convivencia con ellos, hay también valiosas declaraciones en otro reportaje realizado por Alfonso La Torre en el diario Expreso, el año 1974, con motivo de la reedición de Cholerias. Alli se puede constatar que la visión de Meneses es muy diferente a las de Arguedas y Alegria: "Creo ser justo - dice el escritor de Huanta- cuando veo al campesino completo, como a cualquier otro 
hombre, con penas, alegrias, ingenuidad, picardia, maldad. Creo que se ha forjado un clisé del indio peruano: triste, sufrido, vapuleado. Pero no es asi del todo. He alternado con él. No sé si es su naturaleza o el idioma que le permite ser muy irónico". Y más adelante, al hablar sobre la picardia, el humor negro y el espiritu festivo que prevalecen en sus narraciones, Meneses aclara:

"En realidad, en todo el Perú somos muy festivos, nos gusta la diversión; tenemos muchas fiestas patronales, ocasiones de esparcimiento. No la pasamos llorando y sufriendo todo el tiempo. Tengo una visión ademagógica del indio. En la sierra celebran el carnaval un mes; festejan mejor que en Lima las Fiestas Patrias. Eso no denota un espiritu triste o amargado. Ahora, que no hago tampoco un fantoche del indio".

Luego, al referirse a lo último que ha escrito, nuestro narrador dice:

"Tengo varios cuentos nuevos de ambiente cholo; yo debo participar de esa psicología irónica, que puede ser también una defensa contra la dureza que nos rodea. Ahora hay un espíritu más independiente en el indio, pero en el fondo sigue siendo como lo vi. Recién está en trance del cambio, por lo menos en mi tierra, Huanta, en Ayacucho, Huanta fue siempre un pueblo muy rebelde. Su rebeldia ha llenado muchas páginas del siglo pasado. Cuatro o cinco levantamientos masivos, incluso en este siglo? ${ }^{9}$. Es un pueblo decidido, pero que tiene la sabiduria de tratar de disfrutar de la vida".

Finalmente, en el homenaje que le tributó la Universidad Ricardo Palma (2008), Porfirio Meneses leyó un texto notable, sintesis de su visión humana y de su estética, referido a todos los quebrantos, vencidos sin embargo por su exaltación de la vida, por el renacimiento permanente de la belleza, por la conversión de la materia en espíritu y sensibilidad. En el propio prólogo a su traducción de Trilce hay, también, una confesión de vida que se emparenta con el hombre "trilcico":

9 Se refiere al siglo XX. 
"Siempre se dice que el hombre es lo mejor que existe en la naturaleza. No se ha reparado casi nunca en los diversos colores que asume la especie humana, en donde están los luminosos pero también los incuestionablemente oscuros. Y es que los roles que asume tienen dos rostros, de acuerdo con la conducta moral: el blanco y el negro; dos realidades o manifestaciones reveladas a través del carácter, de los gustos y actos, de la vida entera de su total historia. Vallejo internalizó bien este drama desde Los Heraldos Negros, y en Trilce dio al traste con toda la retórica para hablarnos del hombre y de la vida en "caliente". En la profundidad de cada verso suyo el hombre es el más creador, el más bueno e intenso de los seres, y, al mismo tiempo, el peor por los sentimientos y propósitos negativos que son imposibles de controlar u orientar. Ambas realidades tinen, pues, nuestras vidas. Sus sentimientos y reacciones contrapuestas nos llegan traspasados por la sangre que tiñe el papel impreso. Tal es, por ejemplo, cuando el poeta de Santiago de Chuco nos describe sus dolorosas experiencias en la cảrcel. Aqui el "hombre trilcico" representa mejor que nunca a este dolor, a esta naturaleza de lo humano que en sus formas más dañinas y repudiables ensombrecen nuestra existencia". 